\title{
Evaluation of the Relation between Climatic Elements and Rangelands Species Hammada Salicornica
}

\author{
Abdolhossein Yousefi* \\ PhD Student of Climatology, Geography Department, Lorestan University, Khoramabad, Iran, Email: usefi_hossein@yahoo.com \\ Address: 2th St, Dadman, Lar, Fars, Iran, Postal Code:7431811349,Iran, P.O.Box:721,Lar,Iran
}

\section{Dr. Dariush Yarahmadi}

\author{
Assistant Professor of Climatology, Geography Department, Lorestan University, Khoramabad, Iran \\ Email: d.yarahmadi@gmail.com; Address:1th St, Daneshgah,Khoramabad, Lorestan, Iran \\ Postal Code:6815144316, Iran P.O.Box:465,Khoramabad,Iran; Corresponding author: Abdolhossein Yousefi
}

\section{Doi:10.5901/ajis.2015.v4n3p265}

\section{Abstract}

The identification of relation between climatic elements with the distribution of important range species in droughty regions seems necessary in terms of plant conservation and sustainable use of them. It this research in order to evaluate climatic elements effect (temperature, precipitation and humidity) on Hammada salicornica specie plant parameters (density and canopy cover) in Larestan and Tabas regions, Iran. The density and percentage of canopy cover were measured using strip transects and plot establishment. Climatic parameters of temperature, precipitation and relative humidity of particular station in each region were collected and analyzed using SPSS statistical software. Investigation on the correlation degree between climatic and plant parameters in each region showed a significant correlation. So, by using multiple regressions, the decreases in independent climatic parameters and changing them into the parameters which had more effect on the plant dependent parameters were done. Altogether, it was found that the climatic element of the minimum annual temperature average had the most effect on the plant parameters of this specie in both regions.

Keywords: Hammada salicornica, Climate, Range, Regression, Distribution

\section{Introduction}

Rangelands are considered as a part of the natural habitats of a country. These habitats include different plant communities which are affected by climatic factors, soil, organisms and their interactions that have evolved during the past years (Ghaemi et al., 2012). What should be considered in studying the rangeland is that the vegetation is a part of ecosystem and has a close correlation with other parts of the ecosystem including climate ( Zohary, 1973). Therefore, recognition and study of rangelands and presenting a method for it will not be possible without attention to rangelands ecosystem components) (English, 2000). Although plant growth is a function of its genetic specifications, the effects of climatic factors are also important due to their complex relationships with the various stages of plant growth (Nasohi, 2002). Plants growth and vegetation development in one region are affected by different environmental factors such as climate, soil, physiographic and biological factors; as each of these factors are so effective in the plants vital processes. Climate changes and their parameters cause establishment and dominance on specific vegetations in most habitats. In this regard, climate type and important factors such as climate and annual rainfall average, rainfall type, the average annual temperature, thermal absolute limits are effective on plant vegetation (Moghimi,2005). The ecological factors, water and weather conditions are the most important factors affecting vegetation, so that the spatial distribution of vegetation and climate have high correlation with climatic conditions (Sugier, 1996). Therefore, the study of climaticparameters relationship with the distribution of plant species helps us in selection of susceptible species for environmental planning in order to restore and develop rangelands with similar climatic conditions. In long term, we can progress in soil conservation, water and wind-erosion reduction, sand storms and flood damage reduction by settling the selected plant species so that even industrial and population centers adjacent to the rangelands can make benefits from these advantages (Zakeri , 2010). Several natural factors are effective in quantity and quality of pastures or in general, rangelands. Climate has the most important effect on the quantity and quality of rangelands. Suitable climate causes other adverse factors not to occur naturally or their effect to be less (Kardavani, 2010). Precipitation and humidity rates 
which are provided for the growth of the plant play an essential role in the type and composition of vegetation. The amount of precipitation changes also plays a significant role in the vegetation changes (Ghaemi et al.,2012).

However, with regard to the role and plants position in ecosystem balance and different uses of plants either directly by humans or by livestock relationship, it seems essential to determine relationship necessities between plants and climatic parameters for stability and constancy. Hammada salicornica is one of the plants which have broad expansion in warm and dry regions of Larestan and Tabas; it has also been observed in the form of dominant plant or it co-exists with many of plant species. Indeed, it is important in terms of the soil protection and forage production. The type of this plant is perennial, it is also a shrub and from the category of dicotyledonous plants; its family is chenopodiaceae. They are highly resistant to drought specially prolonged droughts. Horizontal and vertical root development sometimes reaches about 4 meters, thus yields more water, and consequently, it is an important mechanism for plant resistance to extreme environmental conditions and lack of moisture. This plant is not only a soil stabilizer plant, but due to high volume and its large crown, it produces considerable fodder (Moghimi,2005).

Demi zadeh (2000), in one research titled "vegetation changes procedure and its relation to rainfall by using satellite images in Southwest of Iran" comes to the conclusion that there is a correlation between vegetation and rainfall. Moisture stored in the soil is one of the most important factors of vegetation growth; it also should be mentioned that vegetation variety can be changed depending on the capacity of the soil moisture. Dashtakian and Khosroshahi (2004), in identifying and introducing vegetation types of desert biomes in Yazd province determined that vegetation types of Hammada salicornica exist mostly in flat lands with low-slope whose features are wind erosion and a clay texture. Tavakoli et al. (2005) have stated some ecological characteristics of Hammada salicornica. He has also said that this plant is expanding in a large part of south region of Iran; it is in fact resistant to drought. Ehsani et al. (2007) conducted one research titled "The Effect of Climate on the Production of Rangelands Forages in Steppe Region of Akhtarabad in Saveh" and concluded that in addition to the previous growing season rainfall index as a variable in the production, it has played a major role, and there is a linear relationship between growing season rainfall and prior production. Zolfaghari Karbasak et al, (2010) examined the correlation between environmental factors and the distribution of vegetation in the basin of Agh Tagheh, and expressed that among investigated environmental factors, there are the most effective factors in the studied area including elevation, slope, carbon, sand, silt, clay and acidity. Ghaemi et al,(2012) investigated vegetation changes of natural rangelands in semi-steppe areas in Bilvar village in Khoy, West Azarbaijan province; they have specified that the correlation between precipitation changes and canopy in most species has been significant during 9 years study in Bilvar protected area.

Silverton et al.,(1994) in their research with the title of "Rainfall, Biomass Variation, and Community Composition" using a 90-year period statistics concluded that there is a significant relationship between biomass and rain. Zaman(1997) in a study on the effects of grazing on production and the vegetation cover percentage of hammada salicornica in Kuwait, came to the conclusion that the plant hammada salicornica is important for grazing. Koc(2001)in his study with the title "Rain fall Effect on rangeland fodder in Turkey" concluded that autumn rainfall has vital effect on rangeland production while dry autumn has no effect on grasses production, but it decreases the growth of legumes and other plant species. In contrast, dry spring and summer have no effect on the production of legumes but grass production is reduced in such conditions. Dougrameji \& karul(1972) in the study of "Sand Dune Reclamation in Iraq: Present Status and Future Prospects" indicated on the use of hammada salicornica for desert reclamation. Ajabnoor et al., (1984) in a biological and phytochemical study of medicinal plants in the Saudi Arabia recognized that plant hammada salicornica contains anti-diabetes drugs. Towhidi(2007) studied nutritional value of some desert plants in Iran which are exposed to camel grazing and stated that Hammada salicornica plant with digestibility of more than 50 percent is a suitable range specie for grazing of camels in the desert region of Yazd.

\section{Materials}

\subsection{Studied areas}

To assess the relationship between climatic factors and range specie of hammada salicornica, some studies have been conducted in the rangelands of Larestan and Tabas cities which are natural habitats of this specie. Their geographical characteristics are as follows: 


\subsubsection{Larestan District:}

Larestan district with an area of 14,157 square kilometers is located in the east-south of Fars Province between $27^{\circ} 21^{\prime}$ to $28^{\circ} 21^{\prime}$ of northern latitude and $53^{\circ} 7^{\prime}$ to $55^{\circ} 44^{\prime}$ of eastern longitude. Area of rangelands in Larestan is 1273543 hectares that about 86920 hectares of which are semi-dense rangelands, and about 1186623 hectares of rangelands are consisted of low-density. District's climate is hot and dry, and the average annual rainfall in the area is $204 \mathrm{~mm}$ and the average annual temperature is $23.6^{\circ} \mathrm{C}$.

\subsubsection{Tabas District:}

Tabas district with an area of 55,460 square kilometers is located in the west of South-Khorasan Province between $31^{\circ} 41^{\prime}$ to $35^{\circ} 3^{\prime}$ of northern latitude and $55^{\circ} 20^{\prime}$ to $58^{\circ} 5^{\prime}$ of eastern longitude. Rangelands in Tabas are 2113653 hectares that about 293,345 hectares of which are semi-dense rangelands and about 1,820,308 hectares of rangelands are of lowdensity. District's climate is hot and dry, and the average annual rainfall in the area is $81.9 \mathrm{~mm}$ and the average annual temperature is $22.6^{\circ} \mathrm{C}$.

\subsection{Botany of hammada salicornica:}

This specie is one of the major plants in arid and desert areas like Larestan and Tabas; it is spreaded as the dominant specie in the broad areas of winter rangelands. The plant color is light green, and when it is dried up, it converts to wax yellow. Its stems are jointed wooden and comes from the soil surface. Estimation of the age of the plant is not possible from the annual circles, due to the twisty and filamentous nature of the stem sections. (Tavakoli et al., 2005). Livestock such as sheep, goat and camel use it while generally sheep and goats graze on it in the late fall and winter (when the leaves are dry), but camel use it all year round. Other feature of this plant is production of sweet latex from breeding organs that form shapes similar to the yellow prayer beads when exposed to air. $32 \%$ of this latex is consisted of two kinds of sugar, glucose and fructose and $33 \%$ sucrose that reduces blood glucose, and it is used in diabetes treatment (Moghimi, 2005). In October when the hammada salicornica begins to flower, honey bees use the pollen of its flowers.

\section{Research Method}

To do this research, using strip transect and plot method, density and canopy cover of the plant parameters were measured with field operations at the habitats of hammada salicornica in Larestan and Tabas cities,. In each district, 90 plots and a total of 180 plots gathered.

Climatic parameters such as annual temperature mean (tm), maximum annual temperature mean (tmh), minimum annual temperature mean (tml), relative annual humidity mean (rh) and annual precipitation mean (pm) were obtained from synoptic stations of Meteorological Agency in Lar and Tabas over a period of 22 years (1991-2012).Also, mentioned climatic parameters were gathered in two climatology stations of Darzousayeban, and Juyom in Larestan district and two climatology stations in Eshgh-Abad and Dihuk in Tabas district over a period of 16 years (1997-2012). In addition, density and canopy as the dependent variables and 5 climatic parameters as independent variables were studied in SPSS for each district.

At first homogeneity of climate and herbal data was tested, and normality of distribution was confirmed with $95 \%$ validity by the Kolmogorov - Smirnov tests which are one of the goodness of fit tests, and they are also parts of nonparametric tests; then correlation between climate and herbal parameters (density and canopy cover) was studied, and there was a significant relationship between climatic and herbal parameters in Larestan and Tabas cities. relationship between climatic parameters and plant parameters were studied with the method of multiple regression analysis, and reduction of the independent variables to the variables that have the most significant effects on the plant dependent variables was carried out.

\section{Results}

The results of the correlation between climatic parameters and herbal parameters in the Larestan district is given in Table 1 and in the district of Tabas is given in Table 2 
Table 1: Correlation Results of Larestan Data

\begin{tabular}{lccccc}
\hline & $\mathrm{pm}$ & $\mathrm{rh}$ & $\mathrm{tm}$ & $\mathrm{tmh}$ & $\mathrm{tml}$ \\
\hline Density & -0.475 & -0.503 & 0.565 & 0.566 & 0.567 \\
\hline Canopy Cover Percent & -0.434 & -0.458 & 0.513 & 0.514 & 0.514 \\
\hline
\end{tabular}

The table of Pearson correlation coefficient variables of Larestan district shows that there is a significant correlation between dependent plant parameters (density and canopy cover) with all studied climatic parameters. This correlation with minimum annual temperature mean, annual maximum temperature mean and annual temperature mean is direct and positive and with annual precipitation mean and annual relative humidity mean is negative and reverse.

Table 2: Correlation Results of Tabas Data

\begin{tabular}{lccccc}
\hline & $\mathrm{pm}$ & $\mathrm{rh}$ & $\mathrm{tm}$ & $\mathrm{tmh}$ & $\mathrm{tml}$ \\
\hline Density & -0.546 & -0.565 & 0.680 & 0.664 & 0.686 \\
\hline Canopy Cover Percent & -0.354 & -0.372 & 0.499 & 0.478 & 0.508 \\
\hline
\end{tabular}

The Pearson table of Tabas district also shows that there is a significant correlation between plant dependent parameters (density and canopy cover) with all studied climatic parameters. There is a direct and positive correlation with minimum annual temperature mean, annual maximum temperature mean and annual temperature mean, and there is a negative and reverse correlation with annual precipitation mean and annual relative humidity mean.

Tables of multiple-regression analysis between climatic parameters (as independent variables) and density parameter of hammada salicornica (as a dependent variable) in Tabas and Larestan districts are as follows:

Table 3: Multiple regression coefficient of dependent density variable in Larestan

\begin{tabular}{cccccc}
\hline \multirow{2}{*}{ Model } & Standard coefficients & \multicolumn{2}{c}{ Non-standard coefficients } & \multirow{2}{*}{ Sig. } & \multirow{2}{*}{$\mathrm{t}$} \\
\cline { 2 - 4 } & Beta & Standard error & B & & \\
\hline Constant & - & 592.957 & -1790.77 & 0.004 & -3.02 \\
\hline tml & 0.567 & 39.793 & 219.163 & 0.000 & 5.508 \\
\hline
\end{tabular}

Table 4: Multiple regression coefficient of dependent density variable in Tabas

\begin{tabular}{|c|c|c|c|c|c|}
\hline \multirow{2}{*}{ Model } & standard coefficients & \multicolumn{2}{|c|}{ Non-standard coefficients } & \multirow{2}{*}{ Sig. } & \multirow{2}{*}{ t } \\
\hline & Beta & Standard error & $B$ & & \\
\hline Constant & - & 593.637 & -2701.395 & 0.000 & -4.551 \\
\hline $\mathrm{tml}$ & 6.925 & 42.609 & 295.064 & 0.000 & 6.925 \\
\hline
\end{tabular}

The above tables show that the dependent density variable only has linear relationship with annual minimum temperature mean (see sig t-statistic value that is less than 0/05). Because zero hypothesis is not rejected, for other climatic parameters the independent variables must be removed from the regression equation.for multiple regression analysis between climatic parameters (as independent variables) and the parameters of the hammada salicornica canopy cover (as the dependent variable) in Tabas and Larestan cities are as follows:

Table 5: Multiple regression coefficients of dependent variable of canopy cover in Larestan

\begin{tabular}{ccccccc}
\hline \multirow{2}{*}{ Model } & standard coefficients & \multicolumn{2}{c}{ Non-standard coefficients } & \multirow{2}{*}{ Sig. } & \multirow{2}{*}{$\mathrm{t}$} \\
\cline { 2 - 4 } & Beta & Standard error & B & & \\
\hline Constant & - & 3.616 & -10.621 & 0.005 & -2.938 \\
\hline tml & 0.514 & 0.243 & 1.163 & 0.000 & 4.795 \\
\hline
\end{tabular}


Table 6: Multiple regression coefficients of dependent variable of canopy cover in Tabas

\begin{tabular}{cccccc}
\hline \multirow{2}{*}{ Model } & standard coefficients & \multicolumn{2}{c}{ Non-standard coefficients } & \multirow{2}{*}{ Sig. } & \multirow{2}{*}{$\mathrm{t}$} \\
\cline { 2 - 4 } & Beta & Standard error & B & & \\
\hline Constant & - & 3.205 & -9.665 & 0.004 & -3.016 \\
\hline tml & 0.508 & 0.230 & 0.997 & 0.000 & 4.336 \\
\hline
\end{tabular}

The above table shows that there is linear relationship between the dependent variable of canopy cover percentage and the minimum annual temperature cover mean (see sig t-statistic value that is less than 0.05 ) and regarding the other climatic parameters it should be mentioned that because zero hypothesis is not rejected, independent variables should be removed from the regression equation.

\section{Discussion and Conclusions}

In this research the relation of climatic elements with plant parameters (density and canopy cover) of hammada salicornica rangeland species was analyzed in order to determine the effective climatic elements on dispersion of this rangeland spiece. Discovering and recognition of relationship between studied climatic and plant parameters of Larestan and Tabas can play a significant role on better understanding of climatic parameters effect on dispersion of hammada salicornica rangeland specie.

The research will identify the species and habitats in the study area and planners and implementers can use it to restore rangeland and habitats to maintain and strengthen vegetation cover their use.In this study, SPSS statistical software was used to identify the most important climatic parameters that are effective on the dispersion of hammada salicornica range species in the habitat of this specie in the Tabas and Larestan cities; also the relationship between climatic parameters and plant parameters (density and canopy cover) of hammada salicornica rangeland species was studied.

At first, using Kolmogorov-Smirnov test investigation on homogeneity of studied climate and herbal data showed that distribution is normal. Then, correlation between climate and plant parameters (density and canopy cover) was studied, and it became revealed there was a significant relationship between climatic and plant parameters in Larestan and Tabas cities.

Using multiple regression analysis, the relationship between climatic and plant parameters was assessed and the reduction change of independent variables to the variables that have the maximum effect on the plant dependent variable took place.

According to the results of this study, Tabas and Larestan's dependent plant variables (density and canopy cover) do enjoy the highest positive and direct correlation with minimum annual temperature mean, maximum annual temperature mean and annual temperature mean; this correlation exists regarding correlation coefficient and the significance level which is at 95\%; meanwhile there is negative and reverse relation between the relative annual humidity mean and annual rainfall mean.

The results of multiple regressions at Larestan district shows that plant-related variables (density and canopy cover) do have a suitable linear relationship with only the minimum annual temperature mean (see sig t-statistic value that is less than 0.05), and about other climatic parameters it should be mentioned that because zero hypothesis is not rejected, as a result the independent variables get excluded from the regression equation. Also the results of multiple regressions at Tabas district shows that plant-related variables(density and canopy cover) do display a suitable linear relationship with only the minimum annual temperature mean (see sig t-statistic value that is less than 0.05 ), and about other climatic parameters it should be said that because zero hypothesis cannot be rejected, as a result the independent variables are excluded from the regression equation. So, the minimum annual temperature mean in both cities are associated with the plant dependent variables of hammada salicornica (density and canopy cover) at the highest level while they play the most important role.

Finally, it is recommended to administrators to closely consider region's annual minimum temperature in their activities during the Reformation, Rehabilitation and Development, also to avoid planting hammada salicornica in areas that are faced with the this constraint. 


\section{References}

Ehsani, A., H., Arzani, M. Farajpor, H. Ahmadi , M., Jafari, A., Jalili, H., Mirdavoudi Akhavan, H., Abbasi, M., Azimi (2007). The effects of climatic conditions on forage harvesting in the steps of Akhtarabad district in Saveh city, Iranian Journal of Range and Desert Research, 14(27).

Tavakoli, H., A. Paryab, Gh. Ghaderi, M. Dashti, (2005). Study of Some Ecological Characteristics of Hammada Salicornica, Iranian Journal of Range and Desert Research, 12(3).211-232

Dashtakian, K., Khosroshahi, (2004). Identification and Introduction of Plant Types in Desert Biomes of Yazd, Iranian Journal of Range and Desert Research, 11(4).383-408.

Dami Zadeh, M, (2000). Satellite data NOAA/AVHRR application in vegetation monitoring. perodical of rangeland and dessert researches in Iran.1(7):27.

Zakeri, O, 2010. Investigation on relation of plant coverage with some physical and chemical properties of soil in Gachin district of Bandar Abbas city. Dissertation of Master of Physical Geography, Faculty of Humanities, Islamic Azad University of Baft, p. 175.

Zolfagari Karbasak, F., A. Bahlavanravi, A. Fakhireh, M. Jabbari, (2010). Investigation of the relationship between environmental factors and the distribution of vegetation in the basin of Agh Tagheh, Iranian Journal of Range and Desert Research, 17(3).431-444.

Ghaemi, M., M. Akbarzadeh, Sh. Abedi, (2012). Investigation of Vegetation Changes of Natural Ranges in Semi-Steppe Area in Bilvar, Khoy, West Azarbaijan Province. Iranian Journal of Range and Desert Research, 19(1).82-94.

Kardovani, P, (2010). Rangelands, problems and solutions of them in Iran. Tehran university press, p. 504.

Moghimi, J., (2005). Introduction to Some Important Range Species, Arvan.p.672.

Nasouhy, Gh., (2002). Meteorology in agriculture, Isfahan Publication, page140.

Ajabnoor, M.A., M.A.yahya, M.Tariq, AA.Jayab.(1984).phytochemical and biological studies on Saudi medicinal planets. Antidiabetic activity of Hammada Salicornica.fitoterapia 55:2,107-109.

Dougrameji,J. and RN, kaul,(1972).sand dune reclamation in Iraq persent status and future prospects. Annals of Arid zone.11:314, 133144.

Englisch,T., 2000. Ecological indicator and correlations whit, soil chemistry, Vienna, Austria, pp. 40

Koc.A.(2001);Autumn and spring drought periods affect vegetation on high elevation Range land of Turkey. J.Range manage. 54:622627.

Silver Town, j, MIKE E. Dodd, Kevin McConway, Jaequelin potts, and mick crawley, (1994).

Rainfall, Biomass variation, and community composition in the park Grass Experiment, Ecology, Vol . 75, No.8(pec.1994),pp.2430-2437.

Sugier,B.(1996).VeA geA tation et atmspheA re.(france:Dominos Flammarion), p:107.

Towhidi, A.,(2007).Nutritive Value of some herbages for dromedary camel in Iran. Pakistan Journal of Biological sciences 10(1):167-170.

Zaman,S.(1997). Effects of rainfall and grazing on vegetation yield and cover of two arid rangelands in Kuwait. Environmental conservation. 24:4, 344-350.

Zohary,M.,(1973).Geobotanical foundations of the Middle East. Guster fischer verlarg. Stuttgart.Swets \& zeitlinger,Amesterdam, pp 42. 